\title{
Deposition and stripping processes of tin on gold film electrodes studied by surface conductance
}

\author{
M. Fonticelli, R.I. Tucceri, D. Posadas* \\ Instituto de Investigaciones Fisicoquímicas Teóricas y Aplicadas, Departamento de Química, Facultad de Ciencias Exactas, \\ Universidad Nacional de La Plata (UNLP), Sucursal 4, Casilla de Correo 16, 1900-La Plata, Argentina
}

Received 29 December 2003; received in revised form 5 June 2004; accepted 7 July 2004

Available online 11 September 2004

\begin{abstract}
The CV and surface conductance (SC) responses of tin species adsorbed on evaporated gold film electrodes were studied as a function of the potential window and the potential sweep rate. Sn adatoms were generated either, by reducing $\operatorname{Sn}(\mathrm{II})$ present in the solution (upd) or by first irreversibly adsorbing $\mathrm{Sn}(\mathrm{II})$ and then reducing it in the supporting electrolyte alone. The experimental results show that at potentials about $E \approx-0.25 \mathrm{~V}$ (versus $\mathrm{SCE}$ ), all the $\mathrm{Sn}(\mathrm{II})$ is reduced to $\mathrm{Sn}(0)$ and this species is adsorbed on the electrode surface. The subsequent oxidation of $\mathrm{Sn}(0)$ leads to $\mathrm{Sn}(\mathrm{II})_{\mathrm{ad}}$, adsorbed on the electrode. This species desorbs only when the $\mathrm{Sn}(\mathrm{II})_{\mathrm{ad}}$ is further oxidised to soluble $\mathrm{Sn}(\mathrm{IV})$. The number of electrons involved in the reduction of $\mathrm{Sn}(\mathrm{II})$ to $\mathrm{Sn}(0)$ and vice versa is two. On the other hand, the analysis of the resistance measurements at low coverage is made by applying the surface Linde's rule. This leads to the conclusion that the $\operatorname{Sn}(0)$ behaves as an interstitial impurity. SC experiments, made in the potential region corresponding to Sn bulk deposition, suggest the formation of a bulk $\mathrm{Sn}-\mathrm{Au}$ alloy.

(C) 2004 Elsevier Ltd. All rights reserved.
\end{abstract}

Keywords: Thin gold film electrodes; Surface conductance; Tin; $u p d$; Bulk deposition

\section{Introduction}

The presence of foreign adatoms on a surface strongly modifies its catalytic properties. This is of particular importance in many electrochemical reactions, particularly those related to hydrocarbon oxidation [1,2]. In this sense, it is interesting to study the modification of the electronic properties of a metal surface by the presence of foreign atoms. One of the methods employed to enquire about these properties is the measure of the surface conductance (SC) changes brought about by the surface impurities [3-7]. SC changes offer the advantage of being sensitive almost exclusively to surface processes [8-13].

$\mathrm{The} \mathrm{Au} / \mathrm{Sn}$ system has received little attention. Bowles et al. $[14,15]$ reported the $u p d$ of tin on platinum electrodes. Vicente and Bruckenstein [16] studied the voltammetric re-

\footnotetext{
* Corresponding author. Tel.: +54 221425 7291; fax: +54 2214254642 . E-mail address: dposadas@inifta.unlp.edu.ar(D. Posadas).
}

sponse of $u p d$ of $\mathrm{Sn}$ (II) on gold by using a rotating gold ring-disk electrode. They found that $\mathrm{Sn}(\mathrm{II})$ in $4 \mathrm{M} \mathrm{HCl}$ is oxidised to $\mathrm{Sn}(\mathrm{IV})$ at $E_{1 / 2}=0.17 \mathrm{~V}$ (versus $\mathrm{SCE}$ ). $\mathrm{Sn}$ (II) is adsorbed at $E<0.2 \mathrm{~V}$ (SCE), but $u p d$ occurs between $-0.6 \mathrm{~V}$ $<E<0.0 \mathrm{~V}$. Bulk deposition of $\operatorname{Sn}(0)$ begins at $E<-0.6 \mathrm{~V}$. More recently, the CV behaviour of Sn on gold was studied by Petersson and Ahlberg [17]. They observed two cathodic peaks. The first one at about $-0.38 \mathrm{~V}$ (versus $\mathrm{Ag} / \mathrm{AgCl}$ ) and the second one at about $-0.5 \mathrm{~V}$. They assigned the first one to the $u p d$ of tin and the second one to their nucleation and growth. B.W. Mao et al., [18] studied by in situ STM, the $\mathrm{Sn} u p d$ on both reconstructed and unreconstructed $\mathrm{Au}\left(\begin{array}{lll}1 & 1 & 1\end{array}\right)$ electrodes. In the case of unreconstructed surfaces they found an immersion of Sn clusters into the substrate surface lattice forming a surface alloy. For the $\mathrm{Au}\left(\begin{array}{lll}1 & 1 & 1\end{array}\right)$ reconstructed surface structural transformations to cordlike structures aligning all in one direction, also involving surface alloying, were detected. $\mathrm{On} \mathrm{Au}(100)$ deposition proceeds in three stages [19]. The first one involves $u p d$ deposits of less than a monolayer. 
The second one comprises the formation of a surface alloy. Finally, there is bulk alloy formation.

Irreversible tin adsorption (ITA) on polyoriented gold has been studied by Rodes et al. [20]. These authors found that ITA, in $0.5 \mathrm{M} \mathrm{H}_{2} \mathrm{SO}_{4}$, shows voltammetric reduction and oxidation peaks at $0.155 \mathrm{~V}$ (versus RHE) and $0.17 \mathrm{~V}$, respectively. These values are coincident with the $u p d$ peak potentials reported in [16]. Based on the $p H$ dependence of the voltammetric peaks, these workers suggest the formation of oxygenated $\mathrm{Sn}$ species during the oxidation of the adsorbed tin adlayer. Rodes et al. [21], have studied the influence of the crystalline orientation of the gold surface structure on the stability of the adsorbed Sn layer. They found the adlayer to be stable provided the electrode potential is kept more negative than $0.25 \mathrm{~V}$ (RHE). Also, they found that adsorbed $\mathrm{Sn}(0)$ oxidises to an oxygenated species of $\mathrm{Sn}(\mathrm{II})$, except in the case of $\mathrm{Au}\left(\begin{array}{lll}1 & 1 & 1\end{array}\right)$ where it oxidises to Sn(IV) directly.

The adsorption of tin on other metals such as Pt [22], Ag [23] and Pd [24] has also been reported.

In this work, we studied the simultaneous $\mathrm{CV}$ and $\mathrm{SC}$ responses of $\mathrm{Sn}$ adatoms on thin gold films obtained by $u p d$ and by ITA. We will also report the SC changes at the begining of the Sn bulk deposition potential region.

\section{Experimental}

Gold thin film electrodes of about $35 \mathrm{~nm}$ thick were grown onto (1 111 ) single crystal silicon substrates under high vacuum conditions. The silicon substrates $(10 \mathrm{~mm} \times 20 \mathrm{~mm}$ and $1 \mathrm{~mm}$ thick) were finally polished with diamond suspension of $0.25 \mu \mathrm{m}$ grain size and cleaned using RCA method [25]. The thin film electrode geometry was similar to that described in [5]. Experiments were performed in a borosilicate glass electrochemical cell specifically designed to facilitate the attachment of a silicon substrate over which the gold thin film was evaporated. The silicon substrate was affixed to the bottom of the electrochemical cell using a silicone rubber sealant (Dow Corning, 3145 RTV). The electrode area exposed to the solution was $0.29 \mathrm{~cm}^{2}$. These electrodes exhibit an initial resistance of about $10 \mathrm{ohms}$. A platinum plate of large area was used as counter electrode. SCE was employed as the reference electrode. All potentials reported in this work are referred to SCE.

Resistance measurements were obtained from the potential drop between the extreme contacts in the gold film while circulating a dc current $(\sim 1 \mathrm{~mA})$. The electrode was electrochemically polarised at an electrical contact equidistant from the two contacts at the extreme of the film [26-28].

The resistance change obtained in this way was recorded as a function of the potential $(\Delta R / R-E)$ together with the voltammetric response $(j-E)$. The experimental set-up for simultaneous voltammetric and surface conductivity measurements on thin film electrodes is described in detail in $[27,28]$.
A PAR Model 173 potentiostat with a PAR Model 175 function generator were used for the voltammetric measurements. The potential drop at the extremes of the film was measured with a Keithley Model 160 voltmeter. An X-Y1-Y2 Hewlett-Packard Model 7046 B plotter was used for simultaneous $\mathrm{CV}$ and $\mathrm{SC}$ records.

AR grade chemicals were used without further purification. The solutions were prepared with previously purified water using a Millipore Milli-Q system and then distilled twice in the presence of alkaline $\mathrm{KMnO}_{4}$.

The irreversible adsorption of Sn(II) was carried out following the procedure of Rodes et al.[20]. The electrode was immersed in a $10^{-2} \mathrm{M} \mathrm{SnSO}_{4}+1 \mathrm{M} \mathrm{H}_{2} \mathrm{SO}_{4}$ solution at open circuit for $30 \mathrm{~min}$. Then, the electrode was carefully rinsed with $1 \mathrm{M} \mathrm{H}_{2} \mathrm{SO}_{4}$ and introduced into the electrochemical cell with an imposed potential of $0.05 \mathrm{~V}$.

\section{Results and discussion}

\subsection{CV and SC responses for the upd of $S n$}

The CV response of a thin gold film electrode immersed in a solution containing $\mathrm{Sn}(\mathrm{II})$ species, for potentials comprised between -0.25 and $0.45 \mathrm{~V}$, is shown in Fig. 1 (solid line). In the potential region comprised between $-0.25 \mathrm{~V}$ and $0.05 \mathrm{~V}$, two peaks are observed. A cathodic one at $E=-0.1 \mathrm{~V}$, corresponding to the underpotential reduction of $S n(I I)$ species, and the corresponding oxidation peak at $E=-0.08 \mathrm{~V}$. At $E$ $=0.2 \mathrm{~V}$ another anodic peak, corresponding to the oxidation of $\mathrm{Sn}(\mathrm{II})$ to $\mathrm{Sn}(\mathrm{IV})$, is observed [16]. This voltammetric response for the $\mathrm{Au} / \mathrm{Sn}(\mathrm{II})$ system is in agreement with that reported by Vicente and Bruckenstein in chloride medium [16] These last authors demonstrated that in the range $-0.6 \mathrm{~V}<$ $E<0.0 \mathrm{~V}, u p d$ of $\operatorname{Sn}(0)$ occurs on the gold surface electrode and also, that the peak at $E=0.2 \mathrm{~V}$ is due to the oxidation

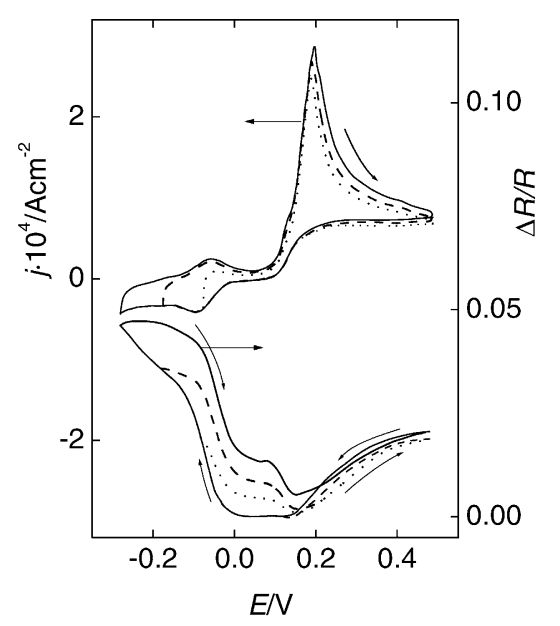

Fig. 1. $j-E$ and $\Delta R / R-E$ responses of a $35 \mathrm{~nm}$ thick gold film electrode in a $10^{-2} \mathrm{M} \mathrm{SnSO}_{4}+1 \mathrm{M} \mathrm{H}_{2} \mathrm{SO}_{4}$ solution for different negative potential limits. Scan rate: $v=0.01 \mathrm{~V} \mathrm{~s}^{-1}$. 
of $\mathrm{Sn}$ (II) to $\mathrm{Sn}(\mathrm{IV})$ as a soluble species [16]. In the presence of $\mathrm{Sn}$ (II) in the solution, the peak at $E=0.2 \mathrm{~V}$ is composed of two contributions [16]: the oxidation of $\mathrm{Sn}(\mathrm{II})_{\mathrm{ad}}$ adsorbed and $\mathrm{Sn}$ (II) coming from the solution. Also, it should be noted the presence of a faradaic current contribution during the cathodic sweep, also reported in the literature [17].

Fig. 1 also shows the $\Delta R / R-E$ response for this $u p d$. Scanning the potential from $0.45 \mathrm{~V}$ towards the negative direction, the resistance first decreases. This is due to the desorption of anions from the supporting electrolyte. This is verified by comparing the $\Delta R / R$ change, in the potential range $0.15 \mathrm{~V}<$ $E<0.45 \mathrm{~V}$, of the blank solution with that of the solution containing the $\mathrm{Sn}(\mathrm{II})$ species. This shows that the $\mathrm{Sn}(\mathrm{II})$ reduction occurs on a gold surface free of adsorbed anions. It should be noted that when the potential scan is started at $0.45 \mathrm{~V}$, the electrode surface is practically free from $\mathrm{Sn}(\mathrm{III})_{\mathrm{ad}}$, as it has been completely oxidised to soluble $\mathrm{Sn}(\mathrm{IV})$ at $0.45 \mathrm{~V}$. When the potential reaches the value at which the reduction of the $\operatorname{Sn}(\mathrm{II})$ starts $(E \approx 0.0 \mathrm{~V})$, the resistance increases. This is due to the reduction of $\mathrm{Sn}$ (II) to $\mathrm{Sn}(0)$, and possibly, to an increase of the adsorption of $\mathrm{Sn}(\mathrm{II})_{\mathrm{ad}}$, since the latter process must be favoured by the decrease of the potential. On inversion of the potential scan direction, $\Delta R / R$ remains nearly constant until the potential corresponding to the oxidation of the previously reduced adsorbed species is reached $(E=-0.1 \mathrm{~V})$, where it starts decreasing. In the potential range comprised between $0.0 \mathrm{~V}$ and $0.1 \mathrm{~V}, \Delta R / R$ shows a plateau that is not coincident with the $\Delta R / R$ value observed during the negative going scan. This plateau is interpreted on the basis of the existence of $\mathrm{Sn}(\mathrm{II})_{\mathrm{ad}}$ species remaining on the gold surface after the oxidation of the $u p d$ tin monolayer as proposed in Ref. [16]. When the potential corresponding to the oxidation of $\mathrm{Sn}(\mathrm{II})$ to $\operatorname{Sn}(\mathrm{IV})(E \sim 0.1 \mathrm{~V})$ is just reached, the resistance further decreases, merging together with that of the blank electrolyte. At this potential complete desorption of $\mathrm{Sn}(\mathrm{II})_{\mathrm{ad}}$ occurs.

Besides, Fig. 1 shows the effect of changing the negative potential limit on both the $\mathrm{CV}$ and the $\mathrm{SC}$ responses. As this limit is made more negative, the amount of the $\operatorname{Sn}(0)$ increases and the corresponding resistance change also increases. This clearly shows that, as in other $u p d$ processes $[3,6,29]$, resistance changes reflect the changes in the amount of adsorbed metal atoms. As the amount of $\operatorname{Sn}(0)$ increases the value of $\Delta R / R$ at the plateau at about $0.0-0.1 \mathrm{~V}$, also increases showing that at this potential, the amount of $\mathrm{Sn}(\mathrm{II})_{\mathrm{ad}}$, has increased. Furthermore, as the negative potential limit is made more negative, the voltammetric response shows a small increase in the peak current of the anodic peak at $E=$ $0.2 \mathrm{~V}$. This fact is attributed to an increased contribution of the $\mathrm{Sn}(\mathrm{II})_{\mathrm{ad}}$ adsorbed on the electrode after the oxidation of the $\operatorname{Sn}(0)$, as shown by the increase of the resistance value at the plateau at about $0.0-0.1 \mathrm{~V}$.

Simultaneous $\mathrm{CV}$ and $\Delta R / R$ responses were obtained at different potential scan rates $(v)$ between $0.01 \mathrm{~V} \mathrm{~s}^{-1}$ and $0.1 \mathrm{~V} \mathrm{~s}^{-1}$, scanning the potential in a smaller potential window $(-0.2 \mathrm{~V}<E<0.1 \mathrm{~V})$. The stabilised $\mathrm{CV}$ and $\Delta R / R$ responses for the $u p d$ of tin are shown in Fig. 2. It should

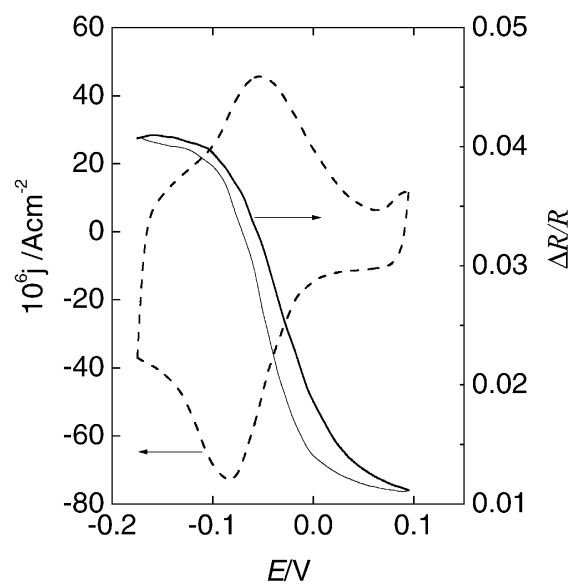

Fig. 2. $j-E(---)$ and $\Delta R / R-E(-)$ responses within the potential range $-0.175 \mathrm{~V}<E<0.1 \mathrm{~V}$. Electrolyte: $10^{-2} \mathrm{M} \mathrm{SnSO}_{4}+1 \mathrm{M} \mathrm{H}_{2} \mathrm{SO}_{4}$ solution; $v=0.1 \mathrm{~V} \mathrm{~s}^{-1}$. A similar film as that indicated in Fig. 1 was employed.

be borne in mind that, since in this potential range $\mathrm{Sn}(\mathrm{II})$ remains adsorbed, the observed $\mathrm{CV}$ response corresponds to the oxidation of $\mathrm{Sn}(0)$ to $\mathrm{Sn}(\mathrm{II})_{\mathrm{ad}}$ and to the reduction of $\mathrm{Sn}(\mathrm{II})_{\mathrm{ad}}$ species. Correspondingly, the $\Delta R / R$ changes only show a closed trace showing the reduction of $\mathrm{Sn}(\mathrm{II})_{\mathrm{ad}}$ to $\mathrm{Sn}(0)$ and vice versa.

\subsection{Voltammetric and surface conductance responses for the irreversibly adsorbed Sn(II)}

The CV of the irreversible adsorbed Sn(II) cycled in the range $-0.17 \mathrm{~V}<E<0.03 \mathrm{~V}$ is shown in Fig. 3 (solid line). The electrode was cycled in this potential range for several hours without change in the $\mathrm{CV}$ response. This indicates that the $\mathrm{Sn}$ remains on the surface as $\mathrm{Sn}(\mathrm{II})_{\mathrm{ad}}$ and as $\mathrm{Sn}(0)$. The reduction charge is equal to the charge required to oxidise $\operatorname{Sn}(0)$ to $\mathrm{Sn}(\mathrm{II})_{\mathrm{ad}}$. When the positive potential limit is increased to include the oxidation to Sn(IV), the following half potential

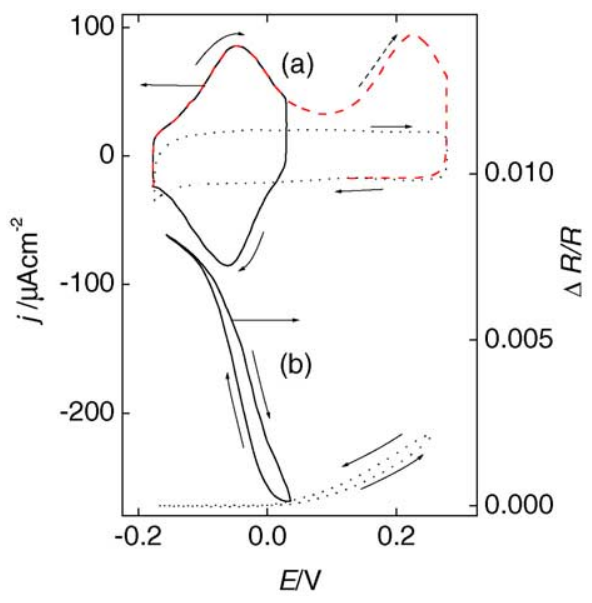

Fig. 3. Stationary $j-E($ a) and $\Delta R / R-E$ (b) responses of irreversibly adsorbed $\mathrm{Sn}:(-)$. First cycle with positive potential limit extended up to $0.28 \mathrm{~V}$ : (-- -); following cycles: $(\cdots)$; electrolyte: $1 \mathrm{M} \mathrm{H}_{2} \mathrm{SO}_{4} ; \nu=0.1 \mathrm{~V} \mathrm{~s}^{-1}$. The charge

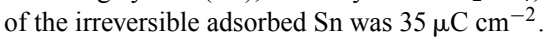


scan shows no cathodic current thus showing that $\mathrm{Sn}(\mathrm{II})_{\mathrm{ad}}$. has almost disappeared in the previous half potential cycle (Fig. 3, dashed line). It is interesting to remark that at $v=$ $0.1 \mathrm{~V} \mathrm{~s}^{-1}$ the charge involved in the oxidation of $\mathrm{Sn}(\mathrm{II})$ to $\mathrm{Sn}(\mathrm{IV})$ is approximately the same as that for the oxidation of $\mathrm{Sn}(0)$ to $\mathrm{Sn}(\mathrm{II})$. This is in agreement with previous finding of Rodes et al. [21]. These experiments allow to draw two important conclusions: $(i)$ all the initial $\mathrm{Sn}(\mathrm{II})_{\mathrm{ad}}$ is reduced to $\mathrm{Sn}(0)$. That is, there is no $\mathrm{Sn}(\mathrm{II})_{\mathrm{ad}}$ remaining on the surface at $E \approx-0.2 \mathrm{~V}$. Otherwise the anodic charge to oxidise $\mathrm{Sn}(\mathrm{II})_{\mathrm{ad}}$ to soluble Sn(IV) would be bigger than the charge employed to oxidize the $\mathrm{Sn}(0)$ to $\mathrm{Sn}(\mathrm{II})_{\mathrm{ad}}$. (ii) The charge involved in the oxidation of $\mathrm{Sn}(0)$ to $\mathrm{Sn}(\mathrm{II})_{\text {ad }}$ is equal to the charge involved to oxidise $\mathrm{Sn}(\mathrm{II})_{\mathrm{ad}}$ to $\mathrm{Sn}(\mathrm{IV})$. This implies that the number of electrons exchanged is the same in both processes, namely two.

The $\Delta R / R$-charge dependence for the oxidation of the $\mathrm{Sn}(0)$ obtained from irreversibly adsorbed tin is practically coincident with that corresponding to the $\operatorname{Sn}(0)$ oxidation process obtained when the potential is cycled in the range $-0.25 \mathrm{~V}<E<0.05 \mathrm{~V}$, in the presence of $\mathrm{Sn}(\mathrm{II})$ in solution. This shows that the surface processes are the same in both cases, that is, the reduction of $\mathrm{Sn}(\mathrm{II})_{\mathrm{ad}}$ to $\mathrm{Sn}(0)$ and vice versa. In both cases, the charge values were obtained from the integration, discounting previously the baseline current, of the corresponding anodic $j-E$ curves from $0.05 \mathrm{~V}$ to $-0.25 \mathrm{~V}$ so that they correspond to the process $\mathrm{Sn}(\mathrm{II})_{\mathrm{ad}} \rightarrow \mathrm{Sn}(0)$. We employ the oxidation charge because during the $u p d$, there is a significant faradaic baseline in the presence of $\mathrm{Sn}(\mathrm{II})$ in solution.

At low coverage, the relative resistance change due to the presence of neutral atomic impurities on a surface can be rationalised employing the surface Linde's rule [3,6,30-32]. This relates the relative resistance change with the surface concentration of the impurity, $\Gamma$, according to:

$\frac{\Delta R}{R}=\left(a+b Z^{2}\right) \Gamma$

where $a$ and $b$ are constants that depend on the substrate and $Z=Z_{\text {ad }}-Z_{\text {sub }}$ if the impurity is a substitional one and $Z=$ $Z_{\text {ad }}$, if it is an interstitial one [6]. $Z_{\text {sub }}$, and $Z_{\text {ad }}$, are the number of valence electrons of the substrate and the adsorbate, respectively. The surface concentration of impurities was obtained from the oxidation charge, $Q: \Gamma=Q / n F, n$ being the number of electrons exchanged $(n=2)$ and $F$ represents the Faraday constant. At low values of $\Gamma$, a plot of $(\Delta R / R)$ versus $\Gamma$ should give a straight line of slope $a+b Z^{2}$. Then, a plot of the slope, $(\Delta R / R) / \Gamma$, against $Z^{2}$, should give a straight line of intercept $a$ and slope $b$. This is shown in Fig. 4 for different adsorbed metals on $\mathrm{Au}$ [6], including some more recent data for Ni [33]. Among these metals, only $\mathrm{Hg}$ and $\mathrm{Sn}$ (see below) behave as interstitial impurities.

As we said above, the $\mathrm{CV}$ profiles corresponding to the experiments in the presence of $\mathrm{Sn}(\mathrm{II})$, show a faradaic contribution to the cathodic current that prevents an accurate estimation of the $u p d$ charge. Therefore, we estimate the charge

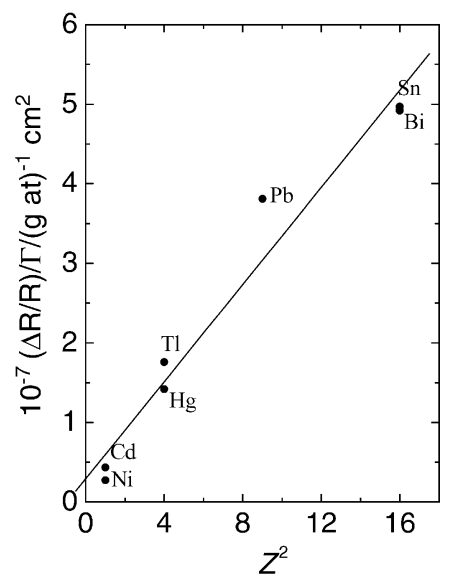

Fig. 4. $(\Delta R / R) / \Gamma$ as a function of $Z^{2}$ for different adatoms involved in $u p d$ and oxidation processes on gold. Data taken from Refs. [6,29,33].

from the anodic curve, which corresponds to the process:

$\mathrm{Sn}(0) \rightarrow \mathrm{Sn}(\mathrm{II})_{\mathrm{ad}}+2 \mathrm{e}$

and in order to apply the Linde's rule, we must consider the process:

$\mathrm{Sn}(\mathrm{II}) \rightarrow \mathrm{Sn}(0)+2 \mathrm{e}$

It is clear that the resistance changes in processes (2) and (3) are different. To obtain the resistance change in process (3), we have to add to the total $\Delta R / R$ change during the $\operatorname{Sn}(0)$ oxidation process, $(\Delta R / R)_{\mathrm{ox}}$ (see full line in Fig. 5), the contribution of the appearing $\operatorname{Sn}(\mathrm{II})_{\mathrm{ad}},(\Delta R / R)_{\mathrm{Sn}(\mathrm{II})} \cdot(\Delta R / R)_{\mathrm{ox}}$ is a function of the oxidation charge. As the resistance decreases during the oxidation process, we will use the charge values obtained from integration of the anodic $j-E$ curve (Fig. 2), starting from $0.05 \mathrm{~V}$ down to $-0.25 \mathrm{~V}$. We will call this charge $Q$. Instead of $Q$, we will use the fraction $Q / Q_{\max }$, were $Q_{\max }$ is the charge obtained integrating from $0.05 \mathrm{~V}$ to the more negative potential $(E=-0.25 \mathrm{~V})$. In this way, $(\Delta R / R)_{\mathrm{ox}}$ increases as $Q / Q_{\max }$ increases (see full line curve in Fig. 5).

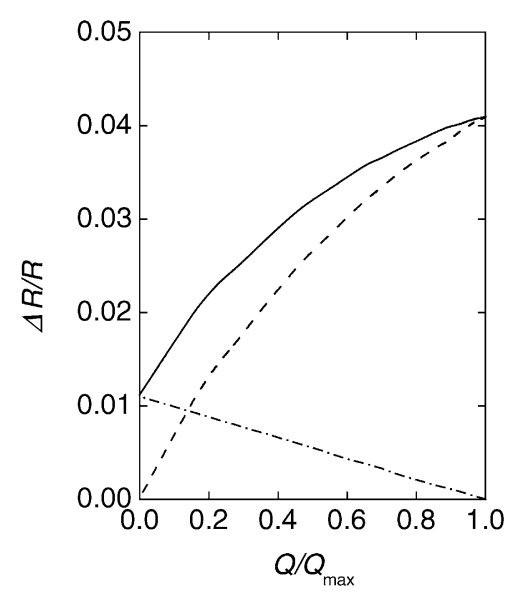

Fig. 5. $\Delta R / R-Q / Q_{\max }$. for the different contributions in Eq. (4): (一) $(\Delta R / R)_{\mathrm{ox}} ;(-\cdots)(\Delta R / R)_{\operatorname{Sn}(\mathrm{II})} ;(---)(\Delta R / R)_{\operatorname{Sn}(0)}$. 
The $(\Delta R / R)_{\mathrm{Sn}(\mathrm{II})}$ values, as a function of the charge, were obtained from the resistance at the plateau at $0.0 \mathrm{~V}<E<0.1 \mathrm{~V}$ in Fig. 1. Note that the $(\Delta R / R)_{\mathrm{Sn}(\mathrm{II})}$ values at the plateau are different because different amounts of $\operatorname{Sn}(0)$ were deposited as a consequence of the increase in the negative potential limit (see Fig. 1). Note also that $(\Delta R / R)_{\operatorname{Sn}(I I)}$, which is a function of $\left[1-\left(Q / Q_{\max }\right)\right]$, appears as decreasing (see slash-dot curve in Fig. 5). Then, the resistance during to process (3), $(\Delta R / R)_{\mathrm{Sn}(0)}$ can be written as:

$$
\begin{aligned}
\left(\frac{\Delta R}{R}\right)_{\operatorname{Sn}(0)}\left(\frac{Q}{Q_{\max }}\right)= & \left(\frac{\Delta R}{R}\right)_{\text {ox }}\left(\frac{Q}{Q_{\max }}\right) \\
& +\left(\frac{\Delta R}{R}\right)_{\operatorname{Sn}(\mathrm{II})}\left[1-\left(\frac{Q}{Q_{\max }}\right)\right]
\end{aligned}
$$

where $\quad(\Delta R / R)_{\text {ox }}\left(Q / Q_{\max }\right), \quad(\Delta R / R)_{\operatorname{Sn}(0)}\left(Q / Q_{\max }\right) \quad$ and $(\Delta R / R)_{\operatorname{Sn}(\mathrm{II})}\left[1-\left(Q / Q_{\max }\right)\right]$ indicates the functional dependence on the charge and not a product. $(\Delta R / R)_{\mathrm{ox}},(\Delta R / R)_{\operatorname{Sn}(0)}$ and $(\Delta R / R)_{\operatorname{Sn}(I I)}$ are shown as a function of $Q / Q_{\max }$ in Fig. 5. From the knowledge of $(\Delta R / R)_{\mathrm{ox}}$ and $(\Delta R / R)_{\mathrm{Sn}(\mathrm{II})}$ and employing Eq. 4 , we obtained $(\Delta R / R)_{\operatorname{Sn}(0)}$. These values were plotted as a function of $\Gamma$. The slope resulted $(\Delta R / R) / \Gamma$ $=4.9710^{7}$ (g at. $)^{-1} \mathrm{~cm}^{2}$. This slope value does not fit in the plot showed in Fig. 4, if $\operatorname{Sn}(0)$ is considered to be a substitutional impurity. However, it fits very well if $\operatorname{Sn}(0)$ is considered an interstitial one $\left(Z=Z_{\mathrm{ad}}\right)$. It is interesting to notice that $\mathrm{Hg}$ also behaves as an interstitial impurity [29] (Fig. 4). This similarity between electrochemical behaviours of mercury and tin deposited on gold, is also evident from the apparent ability of both of them to form alloys with gold [29].

\section{3. $C V$ and $S C$ responses in the region of bulk $S n$ deposition}

When the potential is scanned to values $E<-0.25 \mathrm{~V}$, the cathodic current increases suddenly due to the onset of bulk $\mathrm{Sn}(0)$ deposition (Fig. 6). Reaching a negative potential limit about $-0.45 \mathrm{~V}$, after reversing the potential cycling in the positive direction, a current peak for the stripping process of bulk Sn appears at nearly $-0.23 \mathrm{~V}$ (Fig. 6 , dot-slash line). It is interesting to note that during these potential excursions, the $u p d$ and the corresponding oxidation peaks are slightly increased. The formation of an $\mathrm{Sn}-\mathrm{Au}$ intermetallic phase has been reported by previous workers [17-19]. This behaviour is similar to the oxidation of $\operatorname{Hg}(0)$ on $\mathrm{Au}$, where the stripping of the alloy leads to a broad current peak superimposed on the oxidation of surface $\mathrm{Hg}(0)$ current response [29]. The $\mathrm{CV}$ and the $\mathrm{SC}$ responses are compared in Fig. 6. We do not show SC measurements for potentials more negative than $-0.4 \mathrm{~V}$ since, in the presence of faradaic currents, there is an uneven current distribution at the resistive electrode that interferes with the resistance measurements [26,28]. At potentials where the bulk Sn deposition occurs, the resistance levels off, indicating that there is no increase in the amount

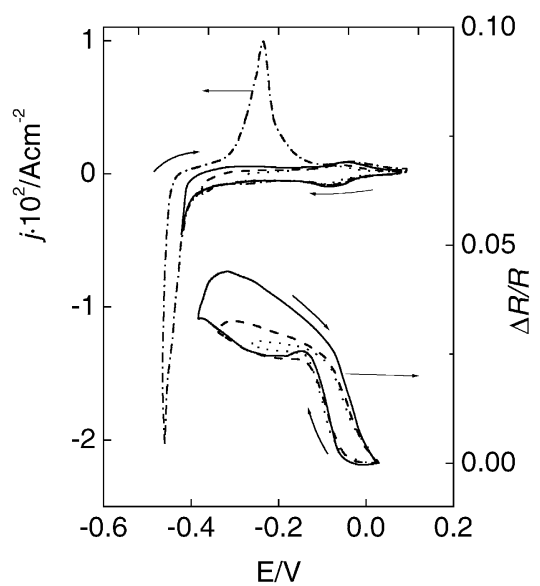

Fig. 6. Stationary $j-E$ and $\Delta R / R-E$ responses of a gold film electrode in a $10^{-2} \mathrm{M} \mathrm{SnSO}_{4}+1 \mathrm{M} \mathrm{H}_{2} \mathrm{SO}_{4}$ solution at different negative potential limits within the region of bulk $\mathrm{Sn}$ deposition. $v=0.1 \mathrm{~V} \mathrm{~s}^{-1}$.

of surface species. As the bulk Sn deposition increases, a small increase in $\Delta R / R$ is noted. Again this is similar to the $\mathrm{SC}$ response of $\mathrm{Hg}-\mathrm{Au}$ alloy reported previously [29]. Upon reversing the potential sweep direction, a further increase of the resistance is noted. The more negative is the potential limit, the higher is the increase of the resistance. This increase, similarly to what happens during mercury deposition on gold with the formation of a bulk $\mathrm{Hg}-\mathrm{Au}$ alloy [29], can be explained by the formation of a bulk $\mathrm{Sn}-\mathrm{Au}$ alloy. As the stripping of the bulk Sn occurs, the resistance shows a maximum, and then decreases again until, eventually, it becomes close to the trace corresponding to the oxidation response of $\mathrm{Sn}(\mathrm{II})_{\mathrm{ad}}$. This shows that the stripping of the Sn from the bulk alloy still continues in the oxidation region of $\mathrm{Sn}(\mathrm{II})_{\mathrm{ad}}$.

\section{Conclusions}

The SC change of a thin gold film electrode during Sn $u p d$ and oxidation processes allows to detect the different tin species present on the gold film surface. In the presence of $\mathrm{Sn}(\mathrm{II})$ in solution, $\mathrm{SC}$ experiments shows that when the positive potential limit is more positive than $0.2 \mathrm{~V}$, the deposition of $\operatorname{Sn}(0)$ adatoms during the negative potential scan occurs on a gold surface initially free from both, adsorbed anions and adsorbed $\mathrm{Sn}(\mathrm{II})$ species. But, as the negative potential limit decreases $(E<0.0 \mathrm{~V})$, both $\mathrm{Sn}(0)$ and $\mathrm{Sn}(\mathrm{II})_{\text {ads }}$ species seems to coexist on the gold surface. However, for enough negative potentials $(E<-0.25 \mathrm{~V})$, all the $\mathrm{Sn}(\mathrm{II})_{\text {ads }}$ is reduced to $\operatorname{Sn}(0)$. During the positive potential scan, the resistance shows a plateau in the potential region $0.0 \mathrm{~V}<E<$ $0.1 \mathrm{~V}$ due to different coverage of $\mathrm{Sn}(\mathrm{II})_{\mathrm{ad}}$ species that have been generated during the $\operatorname{Sn}(0)$ oxidation and that remains adsorbed in this potential range. It is possible to separate the contributions of $\mathrm{Sn}(0)$ and $\mathrm{Sn}(\mathrm{II})_{\mathrm{ads}}$ to the total SC.

SC changes for irreversible adsorbed Sn(II) on the gold film surface compare very well with those obtained under 
upd conditions. CV experiments with irreversible adsorbed Sn allow us to conclude that all the $\mathrm{Sn}(\mathrm{II})_{\mathrm{ad}}$ on the gold surface is reduced to $\operatorname{Sn}(0)$ and that the charge involved in its reduction is equal to the charge involved to oxidise $\mathrm{Sn}(\mathrm{II})_{\mathrm{ad}}$ to Sn(IV), which implies that the number of electrons exchanged in both processes is the same, namely two. The Sn $u p d$ on the gold film surface conforms the Linde's rule if $\mathrm{Sn}(0)$ behaves as an interstitial impurity.

SC experiments in the potential region corresponding to tin bulk deposition on gold suggest the formation of a bulk $\mathrm{Au}-\mathrm{Sn}$ alloy.

\section{Acknowledgements}

We wish to thank D. Schumacher for kindly providing the silicon substrates. M.F. wishes to thank the Consejo Nacional de Investigaciones Científicas y Técnicas (CONICET) for a fellowship. R.I.T and D.P. are members of the Carrera del Investigador Científico of CONICET. Financial support for this work from the Agencia Nacional de Promoción Científico Tecnológica (PICT98/ 06-04012), CONICET, the Comisión de Investigaciones Científicas de la Provincia de Buenos Aires and the Universidad Nacional de La Plata (11/X244) is gratefully acknowledged.

\section{References}

[1] D.M. Kolb, in: H. Gerischer, C.W. Tobias (Eds.), Advances in Electrochemistry and Electrochemical Engineering, vol. 11, Wiley, New York, 1978, p. 125.

[2] R.R. Adzic, in: H. Gerischer, C.W. Tobias (Eds.), Advances in Electrochemistry and Electrochemical Engineering, vol. 13, Wiley, New York, 1985, p. 159.

[3] J.P. Ganon, J. Clavilier, Surf. Sci. 147 (1984) 583.
[4] S.Yu. Vasina, I.P. Gladkikh, G.N. Mansurov, O.A. Petrii, Elektrokhimiya 21 (1985) 953.

[5] C. Hanewinkel, H. Winkes, D. Schumacher, A. Otto, Electrochim. Acta 42 (1997) 3345.

[6] F.M. Romeo, R. Tucceri, D. Posadas, Surf. Sci. 203 (1988) 186.

[7] R.I. Tucceri, D. Posadas, Curr. Top. Electrochem. 3 (1994) 423.

[8] W.J. Anderson, W.N. Hansen, J. Electroanal. Chem. 43 (1973) 339.

[9] W.J. Anderson, W.N. Hansen, J. Electroanal. Chem. 47 (1975) 229.

[10] W.J. Anderson, W.N. Hansen, J. Electrochem. Soc. 121 (1974) 1570.

[11] W.N. Hansen, Surf. Sci. 101 (1980) 109.

[12] D.L. Rath, J. Electroanal. Chem. 150 (1983) 521.

[13] D.L. Rath, W.N. Hansen, Surf. Sci. 136 (1984) 195.

[14] B.J. Bowles, T.E. Cranshaw, Phys. Lett. 17 (1965) 258.

[15] B.J. Bowles, Nature 212 (1966) 1456.

[16] V.A. Vicente, S. Bruckenstein, Anal. Chem. 44 (1972) 297.

[17] I. Petersson, E. Ahlberg, J. Electroanal. Chem. 485 (2000) 178

[18] B.W. Mao, J. Tang, R. Randler, Langmuir 18 (2002) 5329.

[19] J.W. Yang, J. Tang, Y.Y. Yang, J.M. Wu, Z.X. Xie, S.G. Sun, B.W. Mao, Surf. Interface Anal. 32 (2001) 49.

[20] A. Rodes, J.M. Feliu, A. Aldaz, J. Clavilier, J. Electroanal. Chem. 256 (1988) 455.

[21] A. Rodes, E. Herrero, J.M. Feliu, A. Aldaz, J. Chem. Soc. Faraday Trans. 92 (1996) 3769.

[22] N. Furuya, S. Motoo, J. Electroanal. Chem. 98 (1979) 194.

[23] E. Schmidt, J. Electroanal. Chem. 47 (1973) 441.

[24] I. Bakos, S. Szabó, Electrochim. Acta 46 (2001) 2507.

[25] P.C. Searson, in: R.C. Alkire, H. Gerischer, D.M. Kolb, C.W. Tobias (Eds.), Advances in Electrochemical Science and Engineering, vol. 4, VCH, New York, 1995.

[26] R.I. Tucceri, D. Posadas, J. Electrochem. Soc. 130 (1983) 104.

[27] R.I. Tucceri, D. Posadas, J. Electroanal. Chem. 131 (1982).

[28] R.I. Tucceri, D. Posadas, J. Electrochem. Soc. 128 (1981) 1478.

[29] F.M. Romeo, R.I. Tucceri, D.Posadas, Langmuir 6 (1990) 839.

[30] J.W. Geus, in: J.R. Anderson (Ed.), Chemisorption and Reactions on Metallic Films, vol. 1, Academic Press, London, 1971, chapter 5.

[31] J.P. Ziman, Electrons and Phonons. The International Series of Monographs on Physics, Oxford University Press, Oxford, 1972, p. 341.

[32] C. Pariset, J.P. Chauvineau, Surf. Sci. 78 (1978) 478.

[33] M. Fonticelli, D. Posadas, R.I. Tucceri, J. Electroanal. Chem. 553 (2003) 157. 